\title{
MOLECULAR DOCKING STUDIES OF AROMATHERAPY OILS
}

\section{AGAINST SARS-COV-2}

\section{A PREPRINT}

\section{Maurice De Jesus, Jokent T. Gaza, Hiyas Junio, and Ricky Nellas}

Email: rbnellas@up.edu.ph

August 26, 2020

\begin{abstract}
Emerging from Wuhan, China in December 2019, the SARS-CoV-2 virus has spread rapidly, prompting an immediate international response to contain the disease. In this paper, the most abundant volatile compounds in household aromatherapy ointments, namely, methyl salicylate, eucalyptol, $\alpha$-pinene, menthol, camphor, linalool, and trans-pinocarveol were docked to key structures in SARS-CoV-2 invasion: its spike protein, and the human ACE2 and TMPRSS2 proteins. Based on the molecular docking results, the essential oil compounds methyl salicylate, eucalyptol, and $\alpha$ pinene exhibit favorable binding to ACE2 and spike proteins. These compounds may be considered for clinical investigation.
\end{abstract}

Keywords SARS-CoV-2 $\cdot$ aromatherapy $\cdot$ ACE2 $\cdot$ spike protein $\cdot$ TMPRSS2

\section{Introduction}

As of August 2020, the pandemic caused by the SARS-CoV-2 virus has affected more than 200 countries, with over 23 million infected and 800,000 dead. ${ }^{[1]}$ It is known to be transmitted through droplets by infected individuals. ${ }^{[2,3]}$ The onset of symptoms for patients varies greatly, ranging from two to fourteen days after infection. ${ }^{[4]}$ Its effectual disease, COVID-19, originated in Wuhan, China in the winter of 2019. The contagion has spread primarily to neighboring countries, uncontained and undetected. ${ }^{[2,4]}$.

The disease often presents after the fifth day of infection as a case of fever, dry cough, sore throat, and muscular pain. ${ }^{[2]}$ More notable signs of infection are the loss of senses of smell and taste.${ }^{[4]}$ Eventually, COVID-19 progresses 
into difficulty in breathing, acute respiratory distress syndrome, and a complication of severe pneumonia. The elderly and those with underlying health conditions are highly susceptible to infection and will most likely succumb to deterioration $^{[5]}$.

Much of the efforts to uncover SARS-CoV-2 therapeutics involve inhibition of viral entry into host cells. The human angiotensin converting enzyme (ACE2) is the main receptor of the viral spike (S) protein ${ }^{[6]}$. The receptor recognition of spike protein towards ACE2 facilitates the fusion of virus and host cell membranes ${ }^{[7]}$. Another protein involved in the binding of ACE2 and spike protein is the human serine protease TMPRSS2 (transmembrane protease/serine subfamily member 2). This protease primes the spike protein before it binds to ACE2 ${ }^{[8]}$. Camostat mesylate, a clinically approved TMPRSS2 inhibitor prescribed for pancreatitis, caused a reduction in SARS-CoV-2 entry in Calu3 human lung cells ${ }^{[9]}$.

One of the first practices of aromatherapy can be attributed to Ancient Egyptians. They burned scented woods and resins such as frankincense, myrrh, and labdanum to worship and communicate with their gods "by smoke" or in Latin per fumare, from which the word perfume was derived. ${ }^{[10]}$ Incense burning was also part of ancient Chinese civilization, with the smoke used as a demonifuge. ${ }^{[11]}$ Smoke from burning artemisia and grain was used for fumigation to rid of influences of evil spirits, which were believed to cause diseases. ${ }^{[10]}$ Back in the $17^{\text {th }}$ century, miasma or bad smell was once believed to be the principal cause of disease like the plague. ${ }^{[12,13]}$ Some physicians would don masks with curved beaks, which can hold dried flowers, herbs, spices or oils to dispel the "stench of pestilence" to prevent infection. In these contexts, good smell is equated as the foundation of good health.

The Sense of Smell Institute (USA, 1982) defines aromatherapy as "the therapeutic effects of aromas on physical conditions (such as menstrual disorders, digestive problems, etc) as well as psychological conditions (such as depression). ${ }^{[10]}$ This definition encompasses the effect of essential oils (EO) and their components to both mind and body, which is now considered as modern aromatherapy. Reńe-Maurice Gattefossé is largely credited for first introducing the word through his book Aromathérapie in 1937 though his definition is limited only to the physical, physiological and antimicrobial properties of essential oils. ${ }^{[10,14]}$

In modern aromatherapy, delivery of volatile EO can be through direct inhalation, aerial diffusion or topical application. ${ }^{[15,16]}$ Direct inhalation of EO vapors is suggested to alleviate respiratory conditions and colds. Warm water in a container or a warm bath facilitates the slow evaporation of EO for smooth entry into the mouth and nose. Meanwhile, the use of a diffuser to create a fine mist or a burner for fast evaporation are the most common methods for aerial dispersion. For direct application to the skin, a compress or a massage is done. EO drops are added to a hot or cold wet cloth, then the compress is applied to the inflamed or wounded area. Alternately, a liniment, made from EOs or EO blends diluted with carrier oils (e.g. coconut, almond, and sunflower oils), is applied to the area of discomfort with a gentle massage. ${ }^{[10,15]}$

With the growing emphasis on personal health and wellness, there is now a huge market demand for natural therapeutics. Increased sales of EOs for aromatherapy has invigorated the interest to integrate this alternative healing into 
modern medicine. ${ }^{[17]}$ However, there is still a gap in the empirical data to support the curative effects of EOs in aromatherapy. It is argued that the efficacy of EOs are based on their properties as chemical agents, and not really for their odor. A number of studies looked into the activity of EOs, in particular against microorganisms, in liquid and gas form to substantiate this assertion. EO from E. globulus showed significantly better activity in the vapor phase, with 1,8-cineole (34.6 percent), limonene (29.9 percent), and p-cymene (10.5 percent), $\gamma$-terpinene ( 7.4 percent), $\alpha$-pinene (4.0 percent), and $\alpha$-phelandrene (2.4 percent) as major components, against food spoilage microorganisms. ${ }^{[18]}$

Similarly, vapors of cinnamon bark, perilla, and lavender oil showed advantageous activity against microorganism but reduced toxicity in Chinese hamster cells. ${ }^{[19]}$ Specifically, EOs containing phenols and aldehydes (e.g. oregano, thyme, clove, cinnamon bark and lemongrass oils) were found to have the highest vapor activity against the fungi T. mentagrophytes in a survey of 72 EOs. ${ }^{[20]}$ In a related study against pathogenic fungi, oregano, thyme, clove, arborvitae, lavender, and clary sage EOs inhibited the growth of all strains but with varying degrees (fungicidal vs. fungistatic), in both liquid and gaseous state. ${ }^{[21]}$ In the gaseous phase, metabolites are allowed free attachments to the microorganisms while in the liquid phase, lipophilic compounds present in the EO mixture can inhibit attachment through the formation of micelles. ${ }^{[19]}$

The common EO blend consists of menthol and camphor, and oils from eucalyptus, peppermint, lavender, and wintergreen. ${ }^{[22]}$ Mixtures of these volatile essences give off a strong cool minty aroma considered as a panacea for body aches, bruises, headaches and insect bites. For some people, the aroma provides a calming effect when inhaled. Menthol and menthone from peppermint ${ }^{[23]}$ provide the top note of scent, mixed with the other aromatics: methyl salicylate from wintergreen ${ }^{[24]} ; 1,8$ cineole or eucalyptol, $\alpha$-pinene, and trans-pinocarveol from eucalyptus ${ }^{[25]}$; Dcamphor, 1,8-cineole and $\alpha$-terpineol from camphor $\mathrm{EO}^{[26]}$; and linealyl acetate, linalool, and lavandulyl acetate as the major constituents of lavender oil. ${ }^{[27]}$ Some constituents like $\alpha$-pinene, 1,8 -cineole, and camphor are also present in the other EOs but at lower abundance.

Essential oils such as those present in common household ointments are well studied natural products with antiviral activity. ${ }^{[28]}$ Their mechanism of action is by destabilizing virions instead of protecting the host cell or inhibiting replication once the virus invades the host cell ${ }^{[29]}$. Considerable amount of literature identified the activity of various EOs in inhibiting Herpes simplex virus type I infection ${ }^{[30]}$. Other antiviral EOs have bioactivity against yellow fever, dengue, and Junin viruses ${ }^{[31]}$.

This research aims to evaluate how EO components of aromatherapy ointments bind to proteins involved in COVID19 virulence. Determining the interactions between selected ligands and key proteins such as SARS-CoV-2 spike protein and human ACE2 and TMPRSS2 is the first step to harnessing the curative potential of EOs. As a caveat, the findings of this study do not suggest or provide definitive proof of therapeutic effect against SARS-CoV-2 through administration of aromatherapy oils or their components. Results from this study may provide justification and insight to related trials. 


\section{Methodology}

\section{A. Essential oils}

The most common essential oil ingredients are: camphor, menthol, methyl salicylate, eucalyptus oil, lavender oil, and peppermint oil. ${ }^{[32]}$ Eucalyptus oil is mainly composed of $\alpha$-pinene, eucalyptol and trans-pinocarveol. ${ }^{[25]}$ The major components of lavender oil are linalool, camphor and eucalyptol. ${ }^{[33]}$ While, Menthol and eucalyptol mainly comprise peppermint oil. ${ }^{[23]}$

\section{B. Protein preparation}

The structures of the complex of human ACE2 and SARS-CoV spike protein receptor binding domain (RBD) were available in the RCSB Protein Data Bank as accession codes $2 \mathrm{AJF}^{[34]}, 3 \mathrm{SCI}^{[35]}$ and $6 \mathrm{ACK}{ }^{[36]}$. The PDB entry $2 \mathrm{AJF}$ was obtained through x-ray diffraction in 2005 and is of the 2002 SARS-CoV virus. It shows 2 ACE2 and 2 spike protein chains in a heterotetrameric complex. ${ }^{[34]}$ The origin, composition and structural determination method for entry 3SCI is similar to the former and was obtained in 2011. ${ }^{[35]}$ Entry 6ACK is from the same source and was elucidated in 2018 through cryogenic electron microscopy (cryo-EM). Here, a spike protein trimer is complexed to a single ACE2 receptor. ${ }^{[36]}$ Additionally, a recently deposited entry 6M17 obtained using cryo-EM containing a heterohexamer of 2 B(0)AT1 transporter, 2 ACE2 and 2 SARS-CoV-2 spike protein chains was accessible during the time this study was conducted. ${ }^{[37]}$ The structure of TMPRSS2 is a homology model accessible in SwissModel with code O15393 ${ }^{[38]}$. Monomers of human ACE2 and spike protein RBD were single chains derived from the complexes.

\section{Docking and ADME-Tox analysis}

Each of the seven aromatherapy compounds were docked to the nine prepared receptors using AutoDock Vina ${ }^{[39]}$. The docking search space was fit to the bounds of the whole receptor. Afterwards, the binding energy values were recorded and all docking poses were processed using PLIP ${ }^{[40]}$ to determine the interactions between ligands and receptors.

All compounds were subjected to ADMET analysis using the programs SwissADME ${ }^{[41]}$ and ProTox-II ${ }^{[42]}$. The target product profile will depend on remdesivir, a novel antiviral drug for RNA viruses, which has undergone clinical trials for SARS-CoV-2. ${ }^{[43]}$

\section{Results}

The EO compounds have an average binding energy value of $-4.8 \mathrm{kcal} / \mathrm{mol}$ on all receptors. Trans-pinocarveol recorded the lowest average binding energy value across all receptors among the screened compounds. In general, the EOs registered lower binding energy values on the human ACE2 receptors as compared to the SARS-CoV-2 spike proteins. This may be due to the former having more hydrophobic pockets. 
The binding pose of camostat in TMPRSS2 is visualized in Figure 1. In the absence of a crystal structure for the transmembrane serine protease, the homology model provides inferences from similarity regarding the receptor. Based on related proteins, the residues His296, Asp345, and Ser441 facilitate charge transfer ${ }^{[38]}$. The predicted binding site of camostat is distal to the pocket containing these residues, shown in Figure 2. The EO binding sites are nearer the camostat binding region than the charge transfer site, as evidenced by Figure 3 and Table 2. In particular, methyl salicylate shares with camostat much of the binding residues as well as hydrophobic interactions.

The human ACE2 receptor has its catalytic pocket containing Arg273, His345, and His505 [44], and a region that interacts with SARS-CoV-2 spike protein. The latter region consists of helices $\alpha 1$ and $\alpha 2$ plus the linker between sheets $\beta 3$ and $\beta 4$, which are residues numbered 19 to 85 and 351 to $357^{[6]}$. Based on Table 3 and Figure 4 , much of the residues interacting with the ligands are found outside these mentioned regions. Besides camostat, only menthol has a recorded interaction with the catalytic pocket residues. This may mean that all of the EO ligands do not directly interfere with the activity nor with the interaction of human ACE2 with spike protein. Majority of the interactions are with residues Lys562, Leu95, and Val209.

Based on their binding energy values in Table 1, the EO ligands had greater binding to ACE2 as compared to spike protein. Sequence alignment is shown in Figure 5 in order to compare residues among different structures. The residues as well as the sequences for $2 \mathrm{AJF}, 3 \mathrm{SCI}$, and 6ACK spike protein chains were similar to each other, while the numbering on the 6M17 spike protein chain is forward on all amino acids by 13 counts. As shown in Figure 6 and listed in Table 4, binding interactions on the spike protein were almost identical for all EO ligands across the different models. Only Phe334 (or Phe347 for 6M17) was a common interacting residue for the 4 structures.

As shown in Table 5 and Figure 7, most of the EOs are located on ACE2 when docked on the ACE2-spike protein complex. The compounds eucalyptol, $\alpha$-pinene, trans-pinocarveol and methyl salicylate, on the other hand, were found to bind to the spike protein on the interface of the two proteins. Furthermore, the ligands were located on a different region on the complex as compared to their positions on the individual monomers. Compounds that can affect the interaction of spike protein and ACE2 without directly inhibiting ACE2 function could lead to promising new antiviral drugs. These compounds can potentially address the trend of ACE2 and angiotensin receptor inhibitor drugs contributing to further complications and morbidity in COVID-19 patients. ${ }^{[45,46]}$

The essential oil compounds were subjected to ADME-Tox analysis for toxicity and druglikeness prediction. All of the compounds' lipophilicity, solubility, absorption, and distribution predictions passed the consensus criteria of SwissADME, as shown in Table 6. While the evaluation relates to an oral ADME-Tox profile, and that the aromatherapy compounds are administered nasally, ingestion in the nasal route is possible, hence oral toxicity alerts can be relied on. All of the compounds had one automatic leadlikeness violation due to their molecular weights not making the cutoff of $250 \mathrm{~g} / \mathrm{mol}$. Remdesivir was flagged for its size and flexibility, while $\alpha$-pinene went over the lipophilicity limit by a small amount. Three out of the seven EO compounds had $\mathrm{LD}_{50}$ values that were lower than the value predicted for remdesivir, although all compounds were at least categorized as GHS Toxicity Level 4, or generally safe. Methyl sal- 
icylate was predicted to bind to the androgen receptor with high probability, and contain hepatotoxicity with medium probability. Overall, all of the compounds screened were found to be benign. No off-target effects and undesirable toxicity were predicted.

\section{Discussion}

Eastern traditional medicine has long regarded essential oils as therapeutic, providing remedy to a wide range of ailments. Aromatherapy ointments consist of soothing oils, fragrances, and terpenoids. Here, seven essential oil constituents were docked in silico to the proteins ACE2, spike, ACE2-spike complex, and TMPRSS2. Some were found to have significant affinity to COVID-19 related receptors. Overall, trans-pinocarveol was found to bind with least binding energy among the EO compounds.

Inspection of binding interactions reveal that the EOs bind to ACE2 monomer receptors in sites that do not necessarily correspond to the active site nor the spike protein binding interface. For a human ACE2-spike protein model, however, eucalyptol, $\alpha$-pinene and methyl salicylate were found to be located in the spike protein side of the human ACE2-spike protein complex interface (Figure 7). This finding can provide insights on the development of compounds that can disrupt the interaction between the two proteins. A ligand that binds with high affinity to the interface but not with the spike protein could affect the interaction of SARS-CoV-2 through the ACE2 receptor ${ }^{[47]}$.

Understanding how the drug camostat binds to TMPRSS2 through molecular docking also provides valuable insight into the screening and design of antiviral compounds. In this study, camostat bound to TMPRSS2 away from the putative charge transfer pocket of the protease. There is no functional annotation of this region, only that it presents a hinge on the bilobal catalytic chain. ${ }^{[38]}$ Whether or not camostat binding affects its association and priming of the spike protein is a welcome problem to investigate.

On the basis of toxicity, the EOs were evaluated to be generally safe. As a standard, remdesivir was profiled for its ADME-Tox properties in a similar manner as the EO compounds. The drug recently received global attention for having passed early trials on its benefit to COVID-19 cases, though unfortunately, was found to elevate the levels of critical liver enzymes in treated patients. ${ }^{[43]}$ Initially the drug was touted to have an acceptable safety profile before it was promoted for clinical trials. The toxicity evaluation for remdesivir (Table 6) shows a modest toxicity dosage, and a negative result for hepatotoxicity, with an accuracy below 60\%. With regards to this standard for safety, the EO compounds $\alpha$-pinene, eucalyptol, linalool and trans-pinocarveol had lower general estimated risk and can be considered for future trials.

The advantages of EO compounds are their volatility and their intranasal administration. Versus the oral route, the nasal intake of drugs improves their bioavailability. Compound metabolism by hepatic and gastrointestinal enzymes that decrease drug potency will also be avoided. Although in this route, less known nasal mucosa enzymes, olfactory blockages, and other problems innate to the respiratory system can also factor in. ${ }^{[8]}$ Aromatherapy oils, however, are tried and tested compounds of the intranasal route. Around $75 \%$ of the inhaled dose of EOs makes its way into the 
lungs, giving EOs a great advantage in dose efficacy and speed. ${ }^{[49]}$ In the absence of readily available PBPK models specific to nasal delivery of compounds, generalized ADME-Tox profiling by the SwissADME and ProTox-II servers provide suitable prediction.

\section{Conclusion}

Essential oil compounds, such as those present in aromatherapy ointments, provide relief besides their fast soothing of superficial discomfort. Screening bioactive EO compounds could be a step in the right direction. In terms of affinity as calculated by AutoDock Vina, trans-pinocarveol had the lowest binding free energy among the docked EOs across all of the receptors. The compounds eucalyptol, $\alpha$-pinene and methyl salicylate, on the other hand, are found to bind at the interface of the ACE2-spike complex. In general the EO compounds had reported desirable ADME-Tox evaluations, with compounds $\alpha$-pinene, eucalyptol, linalool and trans-pinocarveol scoring better overall in safety as compared to the anti-COVID-19 frontrunner drug remdesivir.

The activation of the SARS-CoV-2 spike protein is facilitated by TMPRSS2. While there is evidence of the action of the drug camostat mesylate in inhibiting TMPRSS2 function and COVID-19 virulence ${ }^{[9]}$, the interactions between receptor and ligand remain undetermined. In this study, methyl salicylate is found to occupy TMPRSS2 on the same site as the inhibitor drug camostat. It is recommended for future studies to find molecular proof of the interactions of camostat and the EO compounds on the serine protease.

As the world races for a cure, volatile oils must be considered in the search for a remedy to the pandemic. Here, in silico evaluation of the binding potential of EOs towards critical COVID-19 receptors was done. Particular EOs of interest are trans-pinocarveol, eucalyptol, $\alpha$-pinene and methyl salicylate. It is recommended to subject these small molecules to future tests, trials, and development. More EO compounds found in smaller concentrations in aromatherapy oils should also be considered for the next docking studies. The focus now shifts to other natural products with similar druglike qualities (e.g. molecular weight, lipophilicity) as drugs in the latest stages of testing.

\section{Acknowledgement}

We acknowledge the Department of Science and Technology-Advanced Science and Technology Institute CoARE Facility and the UP Diliman College of Science Computational Science Research Center (CSRC) for the computing resources.

\section{References}

[1] World Health Organization. Who coronavirus disease (covid-19) dashboard, August 2020. URL https:// covid19.who.int/. 
[2] World Health Organization. WHO Statement regarding cluster of pneumonia cases in Wuhan, China, January 2020. URL https://www.who.int/china/news/detail/ 09-01-2020-who-statement-regarding-cluster-of-pneumonia-cases-in-wuhan-china.

[3] Muhammad Adnan Shereen, Suliman Khan, Abeer Kazmi, Nadia Bashir, and Rabeea Siddique. COVID-19 infection: Origin, transmission, and characteristics of human coronaviruses. Journal of Advanced Research, 24: 91-98, July 2020. ISSN 20901232. doi: 10.1016/j.jare.2020.03.005. URL https : //linkinghub.elsevier . com/retrieve/pii/S2090123220300540.

[4] European Centre for Disease Prevention and Control. Q \& A on COVID-19, March 2020. URL https : //www . ecdc. europa.eu/en/covid-19/questions-answers.

[5] David S. Hui, Esam I Azhar, Tariq A. Madani, Francine Ntoumi, Richard Kock, Osman Dar, Giuseppe Ippolito, Timothy D. Mchugh, Ziad A. Memish, Christian Drosten, Alimuddin Zumla, and Eskild Petersen. The continuing 2019-nCoV epidemic threat of novel coronaviruses to global health - The latest 2019 novel coronavirus outbreak in Wuhan, China. International Journal of Infectious Diseases, 91:264-266, February 2020. ISSN 12019712. doi: 10.1016/j.ijid.2020.01.009.

[6] Penghui Yang and Xiliang Wang. COVID-19: a new challenge for human beings. Cellular \& Molecular Immunology, March 2020. ISSN 1672-7681, 2042-0226. doi: 10.1038/s41423-020-0407-x.

[7] Xiaolu Tang, Changcheng Wu, Xiang Li, Yuhe Song, Xinmin Yao, Xinkai Wu, Yuange Duan, Hong Zhang, Yirong Wang, Zhaohui Qian, Jie Cui, and Jian Lu. On the origin and continuing evolution of SARS-CoV-2. National Science Review, page nwaa036, March 2020. ISSN 2095-5138, 2053-714X. doi: 10.1093/nsr/nwaa036.

[8] Canrong Wu, Yang Liu, Yueying Yang, Peng Zhang, Wu Zhong, Yali Wang, Qiqi Wang, Yang Xu, Mingxue Li, Xingzhou Li, Mengzhu Zheng, Lixia Chen, and Hua Li. Analysis of therapeutic targets for SARS-CoV-2 and discovery of potential drugs by computational methods. Acta Pharmaceutica Sinica B, page S2211383520302999, February 2020. ISSN 22113835. doi: 10.1016/j.apsb.2020.02.008.

[9] Markus Hoffmann, Hannah Kleine-Weber, Simon Schroeder, Nadine Krüger, Tanja Herrler, Sandra Erichsen, Tobias S. Schiergens, Georg Herrler, Nai-Huei Wu, Andreas Nitsche, Marcel A. Müller, Christian Drosten, and Stefan Pöhlmann. SARS-CoV-2 Cell Entry Depends on ACE2 and TMPRSS2 and Is Blocked by a Clinically Proven Protease Inhibitor. Cell, page S0092867420302294, March 2020. ISSN 00928674. doi: 10.1016/j.cell. 2020.02 .052 .

[10] M Lis-Balchin. Aromatherapy with Essential Oils. In K Husnu Can Baser and Gerhard Buchbauer, editors, Handbook of essential oils: science, technology, and applications, pages 549-584. CRC press, 2010.

[11] Olivia Milburn. Aromas, scents, and spices: olfactory culture in china before the arrival of buddhism. Journal of American Oriental Society, 136(3):441-464, 2016.

[12] Pamela Dalton. There' s something in the air: Effects of beliefs and expectations. Olfactory Cognition: From Perception and Memory to Environmental Odours and Neuroscience, 85:23, 2012. 
[13] A Focá and MC Liberto. Historical notes on essential oils and aromatherapy with special reference to bergamot essential oil. In Giacinto Bagetta, Marco Cosentino, and Tsukasa Sakurada, editors, Aromatherapy: Basic Mechanisms and Evidence Based Clinical Use, volume 2, pages 1-16. CRC Press, 2015.

[14] Vicki Pitman. Aromatherapy: a practical approach. Nelson Thornes, 2004.

[15] (editor.) Althea Press. Essential oils for beginners : the guide to get started with essential oils and aromatherapy. Berkeley : Althea Press, 2013.

[16] Andrea Puškárová, Mária Bučková, Lucia Kraková, Domenico Pangallo, and Katarína Kozics. The antibacterial and antifungal activity of six essential oils and their cyto/genotoxicity to human HEL 12469 cells. Scientific reports, 7(1):1-11, 2017.

[17] Hamdy AE Shaaban, Ahmed H El-Ghorab, and Takayuki Shibamoto. Bioactivity of essential oils and their volatile aroma components. Journal of Essential Oil Research, 24(2):203-212, 2012.

[18] Amit Kumar Tyagi and Anushree Malik. Antimicrobial potential and chemical composition of eucalyptus globulus oil in liquid and vapour phase against food spoilage microorganisms. Food Chemistry, 126(1):228-235, 2011.

[19] Shigeharu Inouye, Shigeru Abe, Hideyo Yamaguchi, and Matsumi Asakura. Comparative study of antimicrobial and cytotoxic effects of selected essential oils by gaseous and solution contacts. International Journal of Aromatherapy, 13(1):33-41, 2003.

[20] Shigeharu Inouye, Katsuhisa Uchida, and Shigeru Abe. Vapor activity of 72 essential oils against a Trichophyton mentagrophytes. Journal of Infection and Chemotherapy, 12(4):210-216, 2006.

[21] Judit Krisch, Rentsenkhand Tserennadmid, and Csaba Vágvölgyi. Essential oils against yeasts and moulds causing food spoilage. Science against microbial pathogens: Communicating current research and technological advances, Badajoz, Spain, 2011.

[22] ITMonline. White Flower Analgesic Balm. Available atwww.itmonline.org/jintu/whiteflower. $\operatorname{htm}(2020 / 04 / 08)$.

[23] Erich Schmidt, Stefanie Bail, Gerhard Buchbauer, Ivanka Stoilova, Teodora Atanasova, Albena Stoyanova, Albert Krastanov, and Leopold Jirovetz. Chemical composition, olfactory evaluation and antioxidant effects of essential oil from Mentha x piperita. Natural Product Communications, 4(8):1107-1112, August 2009. ISSN 1934-578X.

[24] Miloš Nikolić, Tatjana Marković, Miloš Mojović, Boris Pejin, Aleksandar Savić, Tamara Perić, Dejan Marković, Tatjana Stević, and Marina Soković. Chemical composition and biological activity of gaultheria procumbens 1. essential oil. Industrial crops and products, 49:561-567, 2013.

[25] Khaled Sebei, Fawzi Sakouhi, Wahid Herchi, Mohamed Khouja, and Sadok Boukhchina. Chemical composition and antibacterial activities of seven Eucalyptus species essential oils leaves. Biological Research, 48(1):7, 2015. ISSN 0717-6287. doi: 10.1186/0717-6287-48-7. URL http://www . biolres . com/content/48/1/7. 
[26] Shanshan Guo, Zhufeng Geng, Wenjuan Zhang, Junyu Liang, Chengfang Wang, Zhiwei Deng, and Shushan Du. The chemical composition of essential oils from cinnamomum camphora and their insecticidal activity against the stored product pests. International journal of molecular sciences, 17(11):1836, 2016.

[27] Sue Clarke. Essential Chemistry for Aromatherapy E-Book. Elsevier Health Sciences, 2009.

[28] Akram Astani, Jürgen Reichling, and Paul Schnitzler. Comparative study on the antiviral activity of selected monoterpenes derived from essential oils. Phytotherapy Research: An International Journal Devoted to Pharmacological and Toxicological Evaluation of Natural Product Derivatives, 24(5):673-679, 2010.

[29] Akram Astani and Paul Schnitzler. Antiviral activity of monoterpenes beta-pinene and limonene against Herpes simplex virus in vitro. Iranian Journal of Microbiology, 6(3):149-155, June 2014. ISSN 2008-3289.

[30] An Overview of the Pharmacological Properties and Potential Applications of Natural Monoterpenes. 14. ISSN 13895575.

[31] Glicerio León-Méndez, Nerlis Pájaro-Castro, Enilson Pájaro-Castro, Miladys Torrenegra-Alarcón, and Adriana Herrera-Barros. Essential oils as a source of bioactive molecules. Revista Colombiana de Ciencias QuímicoFarmacéuticas, 48(1):80-93, January 2019. ISSN 1909-6356, 0034-7418. doi: 10.15446/rcciquifa.v48n1.80067.

[32] Richard Lord. How White Flower oil eased a million aches and pains, and remained a family concern. South China Morning Post, June 2018. URL https://www.scmp.com/lifestyle/health-wellness/article/ 2148656/how-white-flower-oil-eased-million-aches-and-pains-and.

[33] Marietta Białoń, Teresa Krzyśko-Łupicka, Ewa Nowakowska-Bogdan, and Piotr P. Wieczorek. Chemical Composition of Two Different Lavender Essential Oils and Their Effect on Facial Skin Microbiota. Molecules, 24 (18):3270, September 2019. ISSN 1420-3049. doi: 10.3390/molecules24183270. URL https://www.mdpi . com/1420-3049/24/18/3270.

[34] F. Li. PDB ID: 2AJF. Structure of SARS Coronavirus Spike Receptor-Binding Domain Complexed with Receptor. Science, 309(5742):1864-1868, September 2005. ISSN 0036-8075, 1095-9203. doi: 10.1126/science. 1116480 .

[35] Wu, K., Peng, G., Wilken, M., Geraghty, R., Li, F. PDB ID: 3SCI. SARS coronavirus: mechanism of host receptor adaptation and rational prediction of future evolution. doi: DOI:10.2210/pdb3SCI/pdb.

[36] Wenfei Song, Miao Gui, Xinquan Wang, and Ye Xiang. PDB ID: 6ACK. Cryo-EM structure of the SARS coronavirus spike glycoprotein in complex with its host cell receptor ACE2. PLOS Pathogens, 14(8):e1007236, August 2018. ISSN 1553-7374. doi: 10.1371/journal.ppat.1007236.

[37] Renhong Yan, Yuanyuan Zhang, Yaning Li, Lu Xia, Yingying Guo, and Qiang Zhou. Structural basis for the recognition of SARS-CoV-2 by full-length human ACE2. Science, 367(6485):1444-1448, March 2020. ISSN 0036-8075, 1095-9203. doi: 10.1126/science.abb2762.

[38] Andrew Waterhouse, Martino Bertoni, Stefan Bienert, Gabriel Studer, Gerardo Tauriello, Rafal Gumienny, Florian T Heer, Tjaart A P de Beer, Christine Rempfer, Lorenza Bordoli, Rosalba Lepore, and Torsten Schwede. Ho- 
mology model O15393 from: SWISS-MODEL: homology modelling of protein structures and complexes. $\mathrm{Nu}$ cleic Acids Research, 46(W1):W296-W303, July 2018. ISSN 0305-1048, 1362-4962. doi: 10.1093/nar/gky427.

[39] Oleg Trott and Arthur J. Olson. AutoDock Vina: Improving the speed and accuracy of docking with a new scoring function, efficient optimization, and multithreading. Journal of Computational Chemistry, pages NA-NA, 2009. ISSN 01928651, 1096987X. doi: 10.1002/jcc.21334.

[40] Sebastian Salentin, Sven Schreiber, V. Joachim Haupt, Melissa F. Adasme, and Michael Schroeder. PLIP: fully automated protein-ligand interaction profiler. Nucleic Acids Research, 43(W1):W443-W447, July 2015. ISSN 0305-1048, 1362-4962. doi: 10.1093/nar/gkv315.

[41] Antoine Daina, Olivier Michielin, and Vincent Zoete. SwissADME: a free web tool to evaluate pharmacokinetics, drug-likeness and medicinal chemistry friendliness of small molecules. Scientific Reports, 7(1):42717, May 2017. ISSN 2045-2322. doi: 10.1038/srep42717.

[42] Priyanka Banerjee, Andreas O Eckert, Anna K Schrey, and Robert Preissner. ProTox-II: a webserver for the prediction of toxicity of chemicals. Nucleic Acids Research, 46(W1):W257-W263, July 2018. ISSN 0305-1048, 1362-4962. doi: 10.1093/nar/gky318.

[43] Crystal Phend. Remdesivir Safety Forecast: Watch the Liver, Kidneys. MedPage Today, May 2020. URL https://www.medpagetoday.com/infectiousdisease/covid19/86582.

[44] Jodie L. Guy, Richard M. Jackson, Hanne A. Jensen, Nigel M. Hooper, and Anthony J. Turner. Identification of critical active-site residues in angiotensin-converting enzyme-2 (ACE2) by site-directed mutagenesis. FEBS Journal, 272(14):3512-3520, July 2005. ISSN 1742-464X, 1742-4658. doi: 10.1111/j.1742-4658.2005.04756.x.

[45] Murray Esler and Danielle Esler. Can angiotensin receptor-blocking drugs perhaps be harmful in the COVID19 pandemic?:. Journal of Hypertension, 38(5):781-782, May 2020. ISSN 0263-6352. doi: 10.1097/HJH. 0000000000002450 .

[46] Ying-Ying Zheng, Yi-Tong Ma, Jin-Ying Zhang, and Xiang Xie. COVID-19 and the cardiovascular system. Nature Reviews Cardiology, March 2020. ISSN 1759-5002, 1759-5010. doi: 10.1038/s41569-020-0360-5.

[47] Micholas Smith and Jeremy C. Smith. Repurposing Therapeutics for COVID-19: Supercomputer-Based Docking to the SARS-CoV-2 Viral Spike Protein and Viral Spike Protein-Human ACE2 Interface. Preprint, March 2020.

[48] Anaísa Pires, Ana Fortuna, Gilberto Alves, and Amílcar Falcão. Intranasal Drug Delivery: How, Why and What for? Journal of Pharmacy \& Pharmaceutical Sciences, 12(3):288, October 2009. ISSN 1482-1826, 14821826. doi: 10.18433/J3NC79. URL https://journals.library.ualberta.ca/jpps/index.php/JPPS/ article/view/6188.

[49] C. Kohlert, I. van Rensen, R. März, G. Schindler, E. U. Graefe, and M. Veit. Bioavailability and Pharmacokinetics of Natural Volatile Terpenes in Animals and Humans. Planta Medica, 66(6):495-505, August 2000. ISSN 00320943, 14390221. doi: 10.1055/s-2000-8616. URL http://www.thieme-connect.de/DOI/DOI?10. $1055 / \mathrm{s}-2000-8616$. 
[50] Matthew Segall, Edmund Champness, Olga Obrezanova, and Chris Leeding. Beyond Profiling: Using ADMET Models to Guide Decisions. Chemistry \& Biodiversity, 6(11):2144-2151, November 2009. ISSN 16121872, 16121880. doi: 10.1002/cbdv.200900148.

[51] Madison Wynne El-Saadi, Tara Williams-Hart, Brian A Salvatore, and Elahe Mahdavian. Use of in silico assays to characterize the ADMET profile and identify potential therapeutic targets of fusarochromanone, a novel anti-cancer agent. In Silico Pharmacology, 3(1):6, December 2015. ISSN 2193-9616. doi: 10.1186/ s40203-015-0010-5.

[52] Li Wen Shen, Hui Juan Mao, Yan Ling Wu, Yoshimasa Tanaka, and Wen Zhang. TMPRSS2: A potential target for treatment of influenza virus and coronavirus infections. Biochimie, 142:1-10, November 2017. ISSN 03009084. doi: 10.1016/j.biochi.2017.07.016.

[53] Ali A. Rabaan, Shamsah H. Alahmed, Ali M. Bazzi, and Hatem M. Alhani. A review of candidate therapies for Middle East respiratory syndrome from a molecular perspective. Journal of Medical Microbiology, 66(9): 1261-1274, September 2017. ISSN 0022-2615, 1473-5644. doi: 10.1099/jmm.0.000565.

[54] Mushtaq Hussain, Nusrat Jabeen, Anusha Amanullah, Ayesha Ashraf Baig, Basma Aziz, Sanya Shabbir, and Fozia Raza. Structural Basis of SARS-CoV-2 Spike Protein Priming by TMPRSS2. Preprint, Bioinformatics, April 2020. URL http://biorxiv.org/lookup/doi/10.1101/2020.04.21.052639.

[55] Ping Liu, Jing-Zhe Jiang, Xiu-Feng Wan, Yan Hua, Linmiao Li, Jiabin Zhou, Xiaohu Wang, Fanghui Hou, Jing Chen, Jiejian Zou, et al. Are pangolins the intermediate host of the 2019 novel coronavirus (sars-cov-2)? PLoS Pathogens, 16(5):e1008421, 2020.

[56] Helen Sanderson and Judy Ruddle. Aromatherapy and occupational therapy. British Journal of Occupational Therapy, 55(8):310-314, 1992.

[57] Erich Schmidt, Stefanie Bail, Gerhard Buchbauer, Ivanka Stoilova, Teodora Atanasova, Albena Stoyanova, Albert Krastanov, and Leopold Jirovetz. Chemical composition, olfactory evaluation and antioxidant effects of essential oil from Mentha x piperita. Natural product communications, 4(8):1934578X0900400819, 2009. 
Table 1: Binding energies of 7 essential oil compounds to receptors ACE2-spike complex, ACE2 only, spike protein only, and TMPRSS2 (with camostat as standard).

\begin{tabular}{|c|c|c|c|c|c|c|c|c|c|c|c|c|c|}
\hline \multirow[t]{2}{*}{ compound } & \multirow[t]{2}{*}{$\begin{array}{c}\mathrm{MW} \\
(\mathrm{g} / \mathrm{mol})\end{array}$} & TMPRSS2 & & E2-sp & ike & & nding en & ergy (kcal/ & (mol) to & & spike & protein & \\
\hline & & O15393 & $2 \mathrm{AJF}$ & $3 \mathrm{SCI}$ & $6 \mathrm{M} 17$ & 2AJF.A & 3SCI.A & 6ACK.D & $6 \mathrm{M} 17 . \mathrm{B}$ & 2AJF.E & 3SCI.E & 6АCK.A & 6M17.E \\
\hline Menthol & 156.27 & -4.5 & -5.1 & -5.0 & -5.1 & -5.0 & -5.0 & -4.9 & -5.2 & -4.1 & -4.0 & -4.1 & -4.7 \\
\hline Camphor & 152.23 & -4.3 & -5.1 & -5.3 & -4.5 & -5.2 & -5.3 & -4.7 & -4.8 & -3.7 & -3.7 & -3.8 & -4.5 \\
\hline $\begin{array}{r}\text { Methyl } \\
\text { salicylate }\end{array}$ & 152.15 & -4.1 & -4.8 & -4.5 & -5.1 & -4.6 & -4.7 & -5.1 & -5.1 & -3.9 & -3.6 & -3.7 & -4.5 \\
\hline Eucalyptol & 154.25 & -4.0 & -4.9 & -5.3 & -4.7 & -4.8 & -5.3 & -4.8 & -4.7 & -3.8 & -3.8 & -3.7 & -4.9 \\
\hline$\alpha$-pinene & 136.23 & -4.2 & -4.8 & -4.9 & -4.6 & -5.0 & -5.2 & -5.3 & -4.6 & -3.8 & -3.9 & -4.0 & -4.5 \\
\hline $\begin{array}{l}\text { Trans- } \\
\text { pinocarveol }\end{array}$ & 152.23 & -4.4 & -5.1 & -5.2 & -4.8 & -4.9 & -5.4 & -5.3 & -5.0 & -3.8 & -3.9 & -4.0 & -4.8 \\
\hline Linalool & 154.25 & -4.2 & -5.2 & -4.8 & -4.7 & -4.6 & -4.3 & -4.6 & -5.1 & -3.3 & -3.3 & -4.1 & -4.3 \\
\hline Camostat & 398.41 & -6.0 & -7.2 & -7.1 & -6.5 & -6.6 & -7.3 & -7.2 & -6.4 & -5.0 & -5.4 & -5.1 & -5.9 \\
\hline
\end{tabular}


Table 2: List of interactions of essential oil compounds with human TMPRSS2 receptor. Residue text are colored according to the nature of non-covalent bonding to the ligand: black if hydrophobic, red if H-bonding, green if salt bridge, blue if $\pi$-stacking.

\begin{tabular}{l|l}
\hline compound & O15393 \\
\hline$\alpha$-pinene & D220,I221,P369,T481 \\
camphor & D220,P369 \\
eucalyptol & T481 \\
linalool & L373,P375,L404,T407,I425 \\
menthol & L404,T407,E406 \\
methyl salicylate & V149,I221,K223,P369,K223,K223 \\
trans-pinocarveol & D220,T481 \\
camostat & I221,K223,N146,C148,N368,G370,K223,K224
\end{tabular}


Table 3: List of interactions of essential oil compounds with human ACE2 receptors. Residue text are colored according to the nature of non-covalent bonding to the ligand: black if hydrophobic, red if $\mathrm{H}$-bonding, green if salt bridge, blue if $\pi$-stacking.

\begin{tabular}{|c|c|c|c|c|}
\hline compound & 2AJF.A & 3SCI.A & 6ACK.D & 6M17.B \\
\hline$\alpha$-pinene & L95,V209,K562 & L95,V209,P565 & $\mathrm{L} 73, \mathrm{~K} 74$ & $\begin{array}{l}\text { V185,P469,K470,W473,K475, } \\
\text { W478,A673 }\end{array}$ \\
\hline camphor & L95,K562,Q98 & L95,K562 & A99,Q102 & $\begin{array}{l}\text { K475,W478,C530,Q531,H535,P538, } \\
\text { L539,A673,R482,Y613,N674 }\end{array}$ \\
\hline eucalyptol & V209,K562,P565 & L95 & Q98,A99,Q102,K562 & $\begin{array}{l}\text { G466,K470,W473,K475,W478, } \\
\text { P492,N674 }\end{array}$ \\
\hline linalool & F40,W69,L73,N394 & L95,V209,K562,E208,W566 & F32,L73,K74,L100,N103 & $\begin{array}{l}\text { L95,V209,V212,K475,H493,E564, } \\
\text { P565,A673,A396,E489,H493,K562 }\end{array}$ \\
\hline menthol & $\begin{array}{l}\text { L95,V209,K562, } \\
\text { E564,W566 }\end{array}$ & L95,V209,K562,P565,W566 & $\begin{array}{l}\text { L144,D269,W271,F274, } \\
\text { F504,R273,H505 }\end{array}$ & L95,E208 \\
\hline methyl salicylate & $\begin{array}{l}\text { L95,V209,P565, } \\
\text { Q98,K562 }\end{array}$ & L95,V209,K562 & L73,L100,L391,S77 & $\begin{array}{l}\text { L95,P135,N159,E160,W163,V212, } \\
\text { P565,E208,N210,K689,N690,K562 }\end{array}$ \\
\hline trans-pinocarveol & W69,L73,F390,L391 & L95,V209,P565,N210 & F40,F390,L391,D350 & $\begin{array}{l}\text { L95,V209,K475,W478,P492,K562, } \\
\text { E564,P565,A673,D206,R482,K562 }\end{array}$ \\
\hline camostat & $\begin{array}{l}\text { D350,T347,D350, } \\
\text { H378,H401,W349 }\end{array}$ & $\begin{array}{l}\text { Y127,W271,F274,F504,N277, } \\
\text { D269,R273,H505 }\end{array}$ & $\begin{array}{l}\text { L144,W271,F274,F504,N149, } \\
\text { N277,R273,H505,F274,F504 }\end{array}$ & $\begin{array}{l}\text { D350,F390,R393,K475,L675,N394, } \\
\text { K475,R482,N674,E489,R644 }\end{array}$ \\
\hline
\end{tabular}


Table 4: List of interactions of essential oil compounds with spike protein (receptor binding domain) receptor. Residue text are colored according to the nature of non-covalent bonding to the ligand: black if hydrophobic, red if H-bonding, green if salt bridge, blue if $\pi$-stacking.

\begin{tabular}{|c|c|c|c|c|}
\hline compound & 2AJF.E & 3SCI.E & 6ACK.A & 6M17.E \\
\hline$\alpha$-pinene & W340,R342,R453 & W340,R342 & V404,I405,Y440,Y442 & V341,A344,N354 \\
\hline camphor & Y438,S336 & W340,R342,R453 & V404,I405,Y440 & F347,N354,R346 \\
\hline eucalyptol & W340,R342 & W340,R342,R453 & V404,I405,Y440,Y442 & A344,F347,S399 \\
\hline linalool & N437,Y438,K439 & W340,R342 & V404,I405,Y440,I405 & $\begin{array}{l}\text { F342,L368,F374, } \\
\text { W436,N343 }\end{array}$ \\
\hline menthol & A339,N437,Y438,K439 & W340 & V404,I405,Y440,Y442 & $\begin{array}{l}\text { T376,K378,V407, } \\
\text { R408,V433 }\end{array}$ \\
\hline methyl salicylate & Y338,K439,F334,S336 & W340,R342,R342 & V404,I405,Y440,Q396,K390 & $\begin{array}{l}\text { T376,K378,V407, } \\
\text { A411,V433,K378 }\end{array}$ \\
\hline trans-pinocarveol & A339,Y438,K439,F334 & W340,R342 & V404,I405,Y440,Y442 & $\mathrm{R} 457, \mathrm{Y} 473, \mathrm{P} 491$ \\
\hline camostat & $\begin{array}{l}\text { W340,R342,E452,R342, } \\
\text { P450,E452,R453 }\end{array}$ & $\begin{array}{l}\text { R342,E452,R342, } \\
\text { P450,E452,W340 }\end{array}$ & $\begin{array}{l}\text { V404,I405,Y408,Y442, } \\
\text { Q396,V404,I405,K447 }\end{array}$ & $\begin{array}{l}\text { F342,F374,W436,S371, } \\
\text { S373,N437,W436 }\end{array}$ \\
\hline
\end{tabular}


Table 5: List of interactions of essential oil compounds with ACE2-spike protein complex receptors. Residue text are colored according to the nature of non-covalent bonding to the ligand: black if hydrophobic, red if H-bonding, green if salt bridge, blue if $\pi$-stacking. Residues belong to the ACE2 receptor unless stated otherwise.

\begin{tabular}{|c|c|c|c|}
\hline compound & $2 \mathrm{AJF}$ & 3SCI & $6 \mathrm{M} 17$ \\
\hline$\alpha$-pinene & W69,L73,F390,L391 & (spike) E35,D38,L39,Y436,D480 & L95,K475,E479,P492,K562,P565 \\
\hline camphor & L95,K562,K562 & L95,K562 & $\begin{array}{l}\text { P135,N159,E160,W163,E527,C530, } \\
\text { H535,L539,E527,Q531,S692 }\end{array}$ \\
\hline eucalyptol & (spike) Y436,D480 & L95 & L95,K470,W473,K562,W566 \\
\hline linalool & F40,W69,F390,L391 & $\mathrm{F} 40, \mathrm{~W} 69, \mathrm{~F} 390$ & $\begin{array}{l}\text { F40,G352,F390,R393,K475,H493, } \\
\text { A673,R393,N394,E489 }\end{array}$ \\
\hline menthol & F40,W69,F390,L391,R393 & F32,W69,L73,L100,F390 & $\begin{array}{l}\text { L95,V209,N210,K475,W478,R482, } \\
\text { P565,W566,E489,H493,P565 }\end{array}$ \\
\hline methyl salicylate & F390,D350,R393,F40 & (spike) E35,D38,N479,E35 & L95,V212,K562,E208,N210 \\
\hline trans-pinocarveol & F40,W69,F390,L391,R393 & $\begin{array}{l}\text { (spike) E35,D38,L39,N479, } \\
\text { D480,E35,N479,D480 }\end{array}$ & $\begin{array}{l}\text { L95,V209,K475,W478,P492,K562, } \\
\text { A673,A396,R482,W566 }\end{array}$ \\
\hline camostat & F40,L73,L100,S77,D350,F390 & $\begin{array}{l}\text { L144,E145,W271,L503, } \\
\text { F504,Y127,S128,E145, } \\
\text { N149,R273,Y127 }\end{array}$ & $\begin{array}{l}\text { F40,P135,D350,F390,K689, } \\
\text { N134,E166,G395,E668,V670, } \\
\text { E171,K174,H401 }\end{array}$ \\
\hline
\end{tabular}


Table 6: ADME-Tox predictions for the selected essential compounds and remdesivir. Key: PGH1 = prostaglandin G/H synthase 1 or cyclooxygenase 1, ANDR = androgen receptor, AOFA = monoamine oxidase A. Organ toxicity predictions ("POS" for positive and "NEG" for negative) are reported with the corresponding prediction accuracy.

\begin{tabular}{|c|c|c|c|c|c|c|c|c|}
\hline & $\alpha$-pinene & camphor & methyl salicylate & eucalyptol & linalool & trans-pinocarveol & menthol & remdesivir \\
\hline Consensus $\log \mathrm{P}$ & 3.44 & 2.37 & 1.66 & 2.67 & 2.66 & 2.1 & 2.58 & 1.53 \\
\hline $\begin{array}{l}\text { Consensus } \\
\text { solubility }\end{array}$ & Soluble & Soluble & Soluble & Soluble & Soluble & Very soluble & Soluble & $\begin{array}{l}\text { Moderately } \\
\text { soluble }\end{array}$ \\
\hline GI absorption & Low & High & High & High & High & High & High & Low \\
\hline BBB permeant & Yes & Yes & Yes & Yes & Yes & Yes & Yes & No \\
\hline $\begin{array}{l}\text { Bioavailability } \\
\text { score }\end{array}$ & 0.55 & 0.55 & 0.55 & 0.55 & 0.55 & 0.55 & 0.55 & 0.17 \\
\hline $\begin{array}{l}\text { Leadlikeness } \\
\text { violations }\end{array}$ & 2 & 1 & 1 & 1 & 1 & 1 & 1 & 2 \\
\hline $\begin{array}{l}\text { Predicted LD50 } \\
(\mathrm{mg} / \mathrm{kg})\end{array}$ & 3700 & 775 & 887 & 2480 & 2200 & 1800 & 940 & 1000 \\
\hline $\begin{array}{l}\text { High probability } \\
\text { binding target }\end{array}$ & PGH1 & ANDR & ANDR & & & PGH1 & ANDR & (no prediction) \\
\hline $\begin{array}{l}\text { Moderate probability } \\
\text { binding target }\end{array}$ & & & & ANDR & & AOFA & & (no prediction) \\
\hline Hepatotoxicity & NEG, $86 \%$ & NEG, $72 \%$ & POS, $55 \%$ & NEG, $86 \%$ & NEG, $76 \%$ & NEG, $77 \%$ & NEG, $77 \%$ & NEG, $56 \%$ \\
\hline Carcinogenicity & NEG, $60 \%$ & NEG, $68 \%$ & NEG, $71 \%$ & NEG, $68 \%$ & NEG, $64 \%$ & NEG, $67 \%$ & NEG, $89 \%$ & NEG, $55 \%$ \\
\hline Immunotoxicity & NEG, 99\% & NEG, $96 \%$ & NEG, $97 \%$ & NEG, $99 \%$ & NEG, $99 \%$ & NEG, $97 \%$ & NEG, 99\% & NEG, $90 \%$ \\
\hline Mutagenicity & NEG, 93\% & NEG, $94 \%$ & NEG, $96 \%$ & NEG, $96 \%$ & NEG, $95 \%$ & NEG, $85 \%$ & NEG, $73 \%$ & NEG, $62 \%$ \\
\hline Cytotoxicity & NEG, $75 \%$ & NEG, $61 \%$ & NEG, $84 \%$ & NEG, $75 \%$ & NEG, $82 \%$ & NEG, $84 \%$ & NEG, $88 \%$ & NEG, $55 \%$ \\
\hline
\end{tabular}




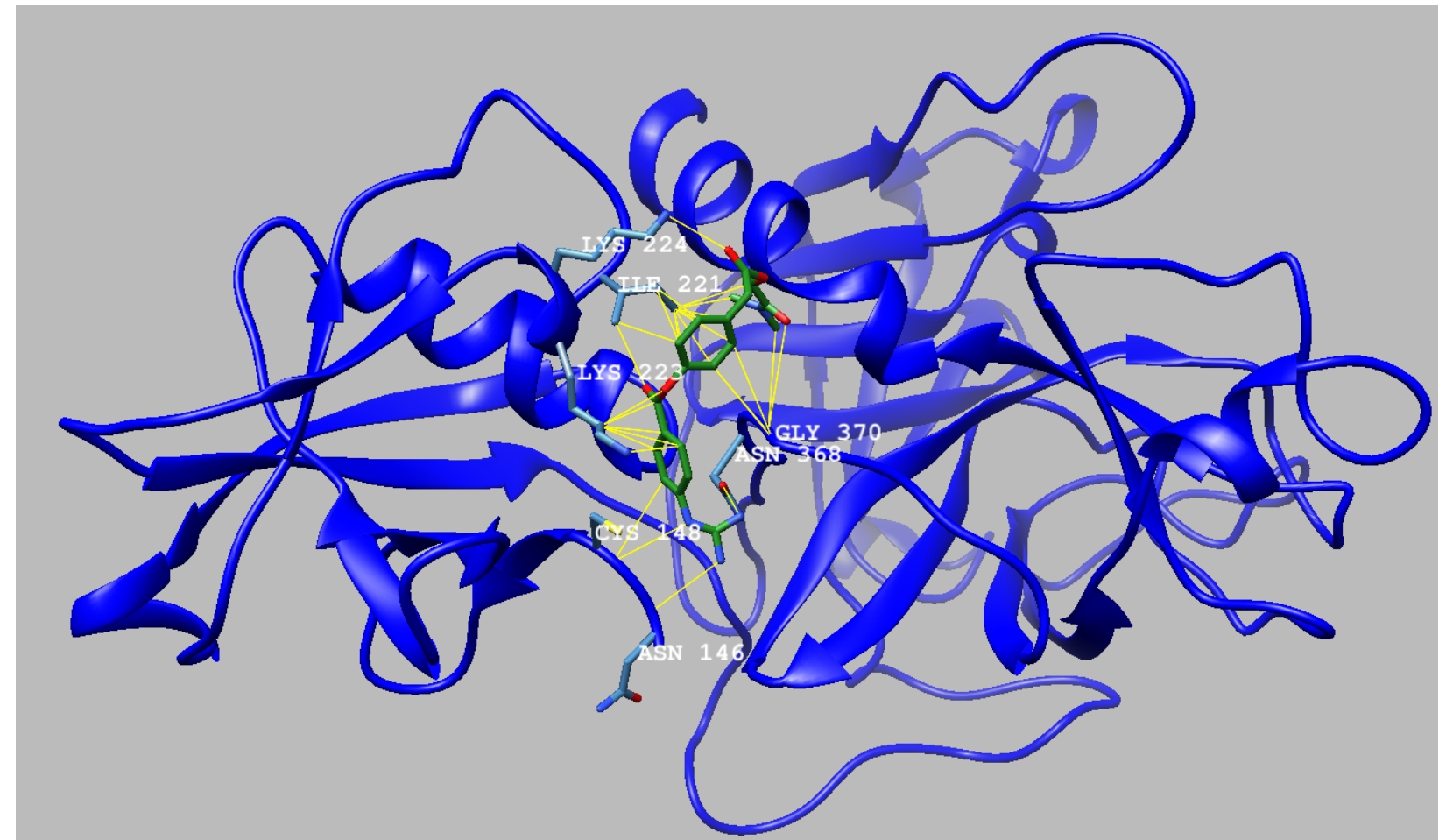

Figure 1: Docking pose of camostat in TMPRSS2 homology model O15393, with interactions to protein residues depicted by yellow lines. 


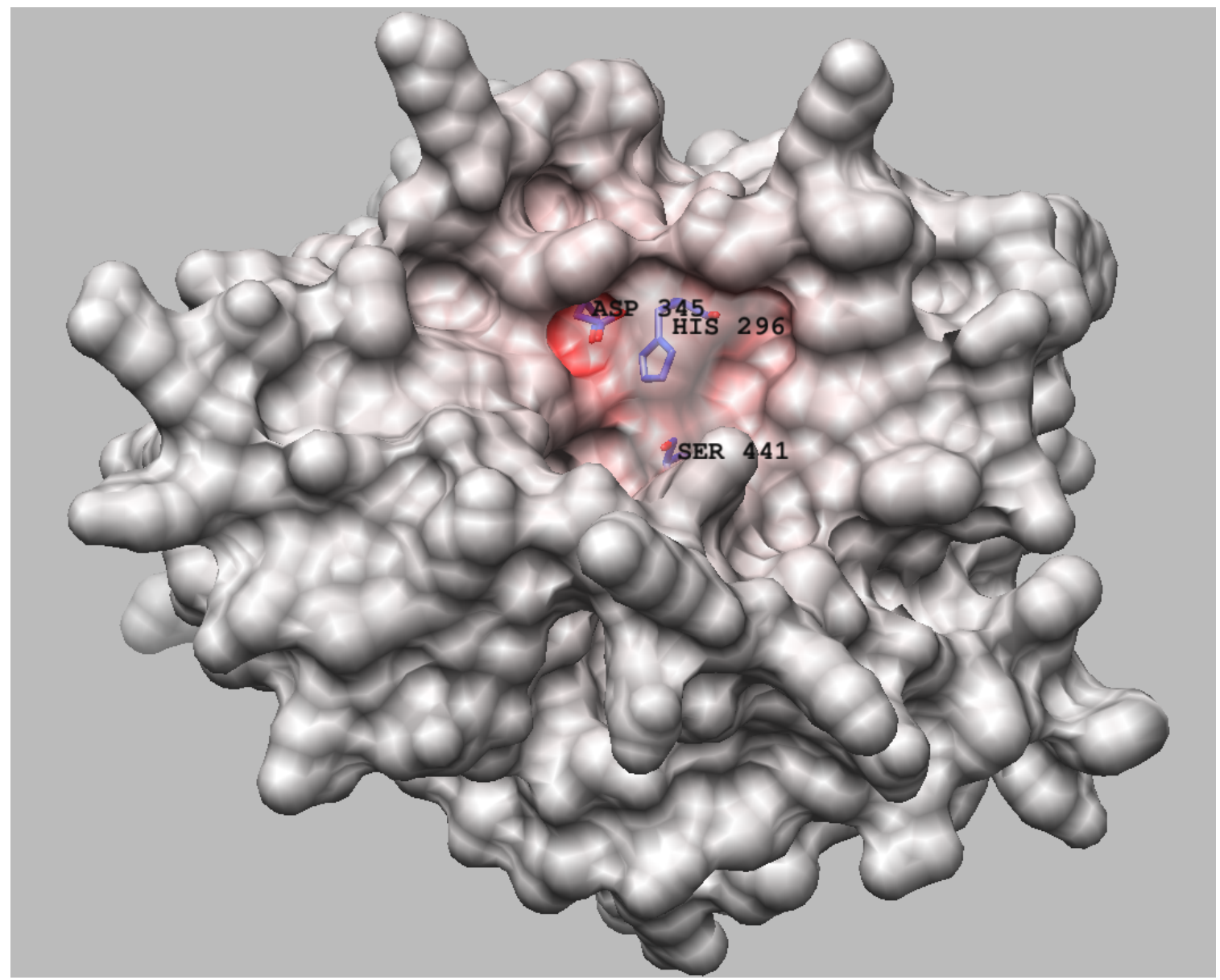

Figure 2: The charge transfer residues of TMPRSS2 located in a hydrophobic binding pocket. 


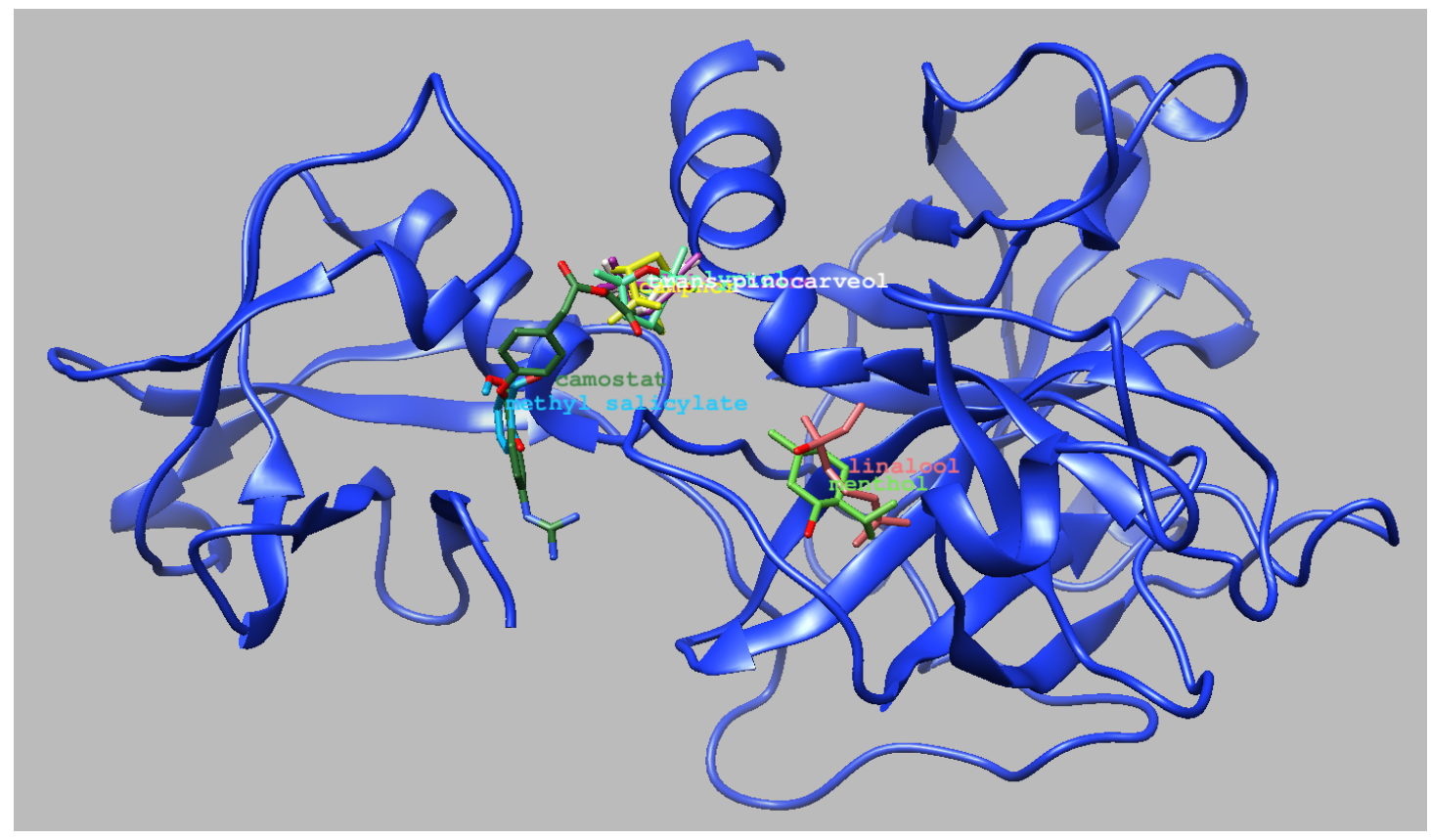

Figure 3: Docking of essential oils and camostat to TMPRSS2 (homology model O15393). 


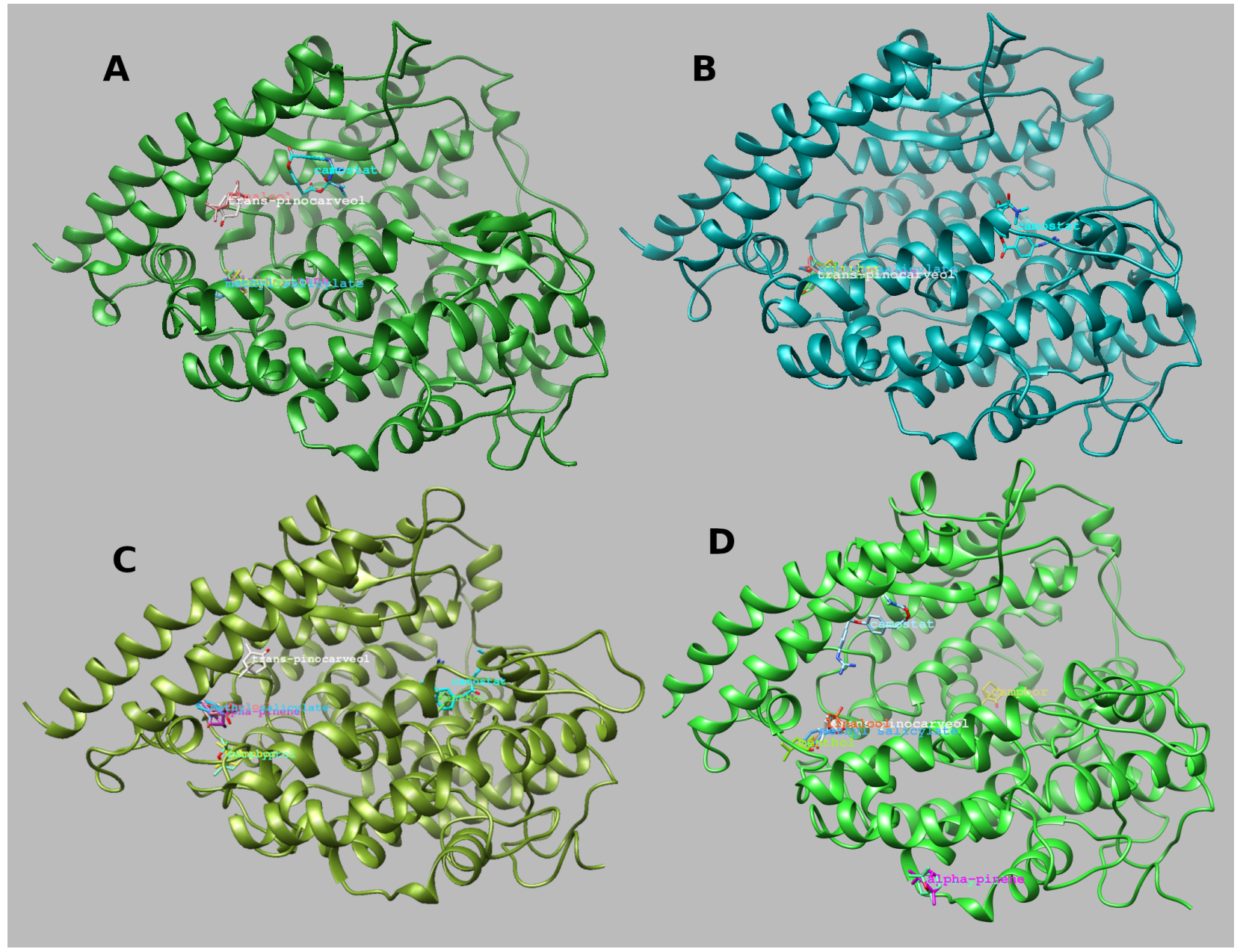

Figure 4: Docking of essential oils and camostat to ACE2 (A: 2AJF.A, B: 3SCI.A, C: 6ACK.D, and D: 6M17.B). 


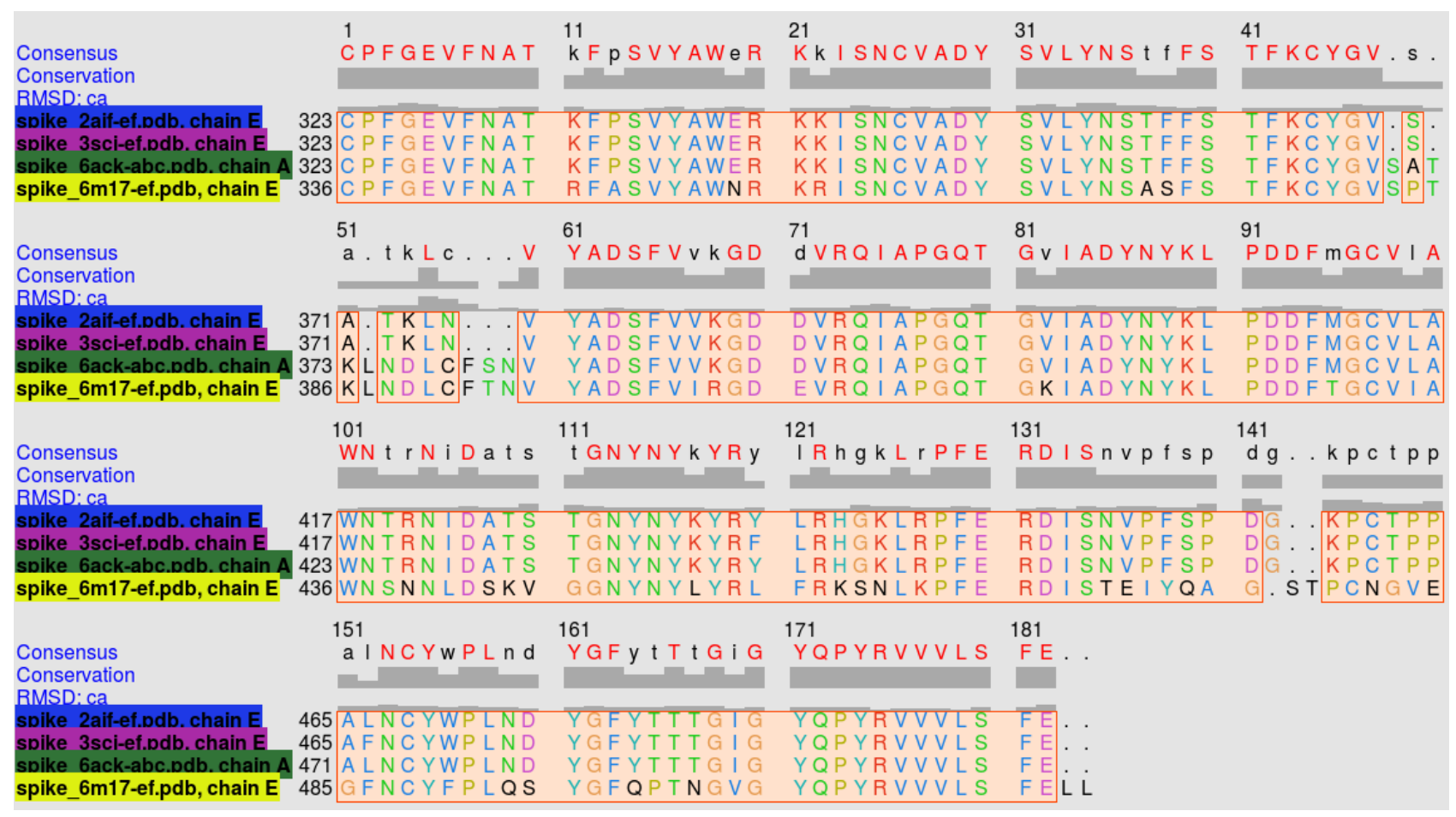

Figure 5: Alignment of spike protein chains from 2AJF, 3SCI, 6ACK and 6M17. Sequence alignment was performed using UCSF Chimera. 


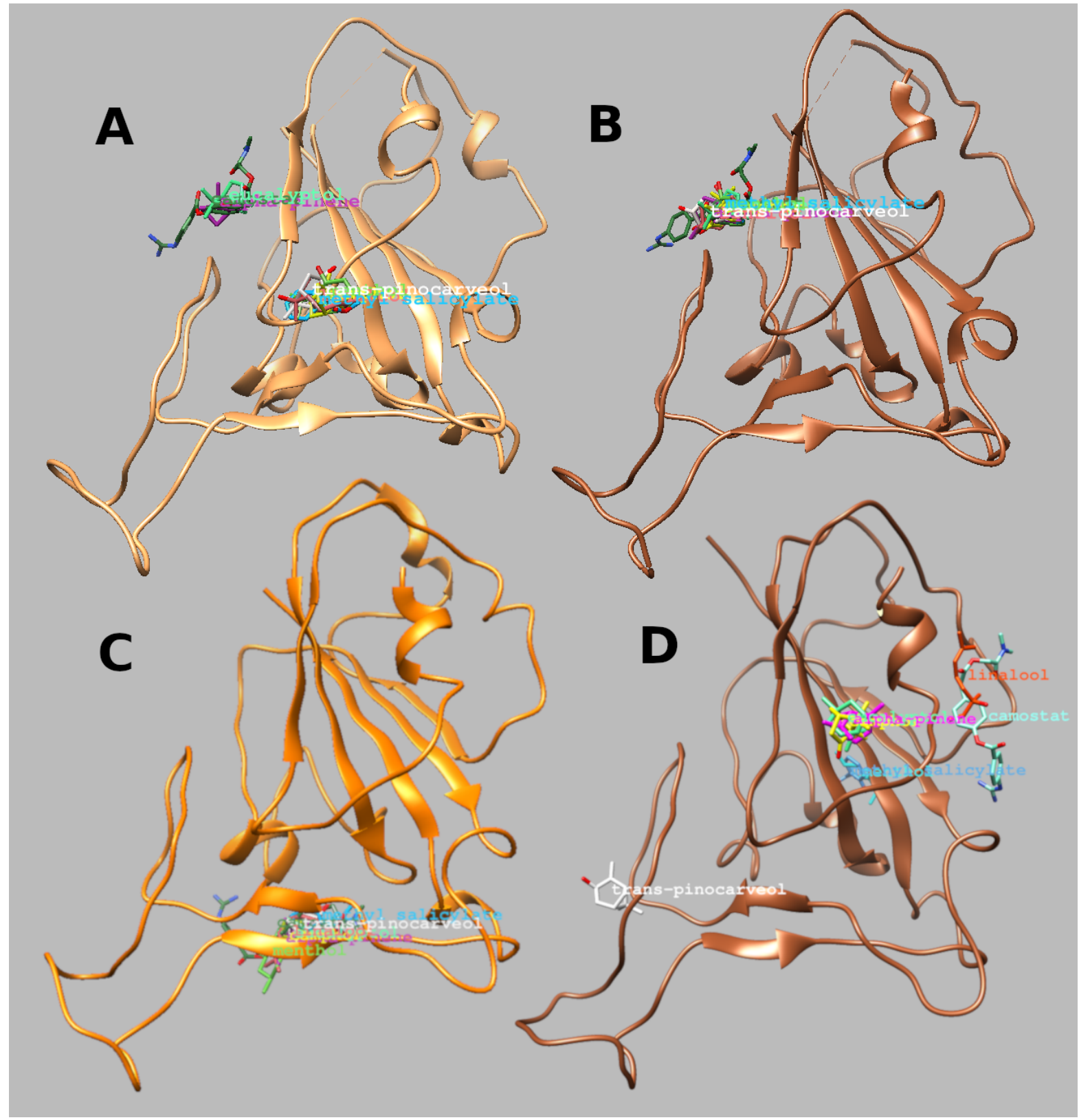

Figure 6: Docking of essential oils and camostat to spike protein (A: 2AJF.E, B: 3SCI.E, C: 6ACK.A, and D: 6M17.E). 


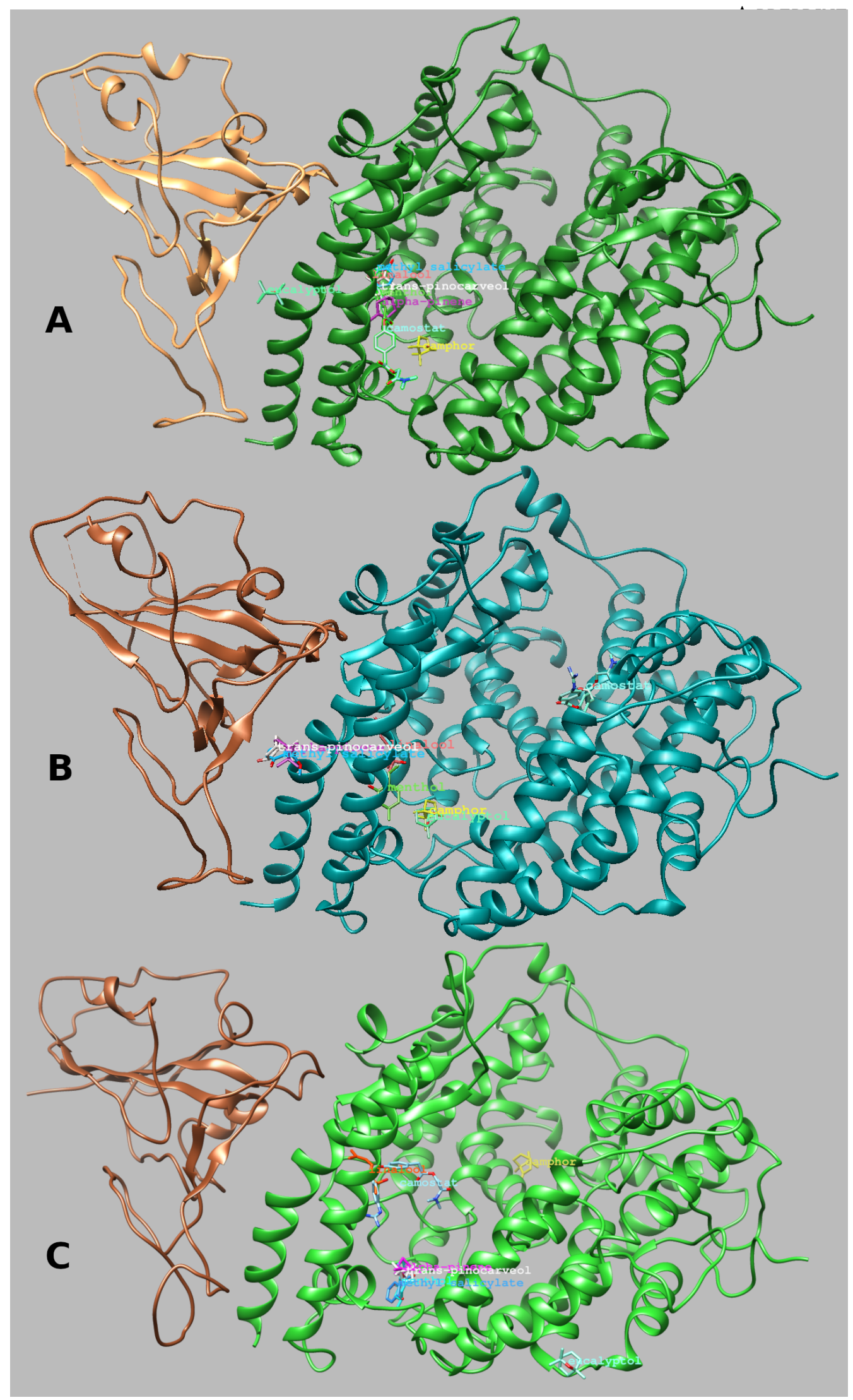

August 26, 2020

Figure 7: Docking of essential oils and camostat to ACE2-spike protein RBD complex (A: 2AJF.AE, B: 3SCI.AE, and C: 6M17.BE). 